\title{
Direct Method Cash Flow Statements: Their Time Has Come
}

Harley M. Courtney, (E-mail: Courtney@uta.edu), University of Texas, Arlington Roberta Ann Jones, (E-mail: rjones1@ pittstate.edu), Pittsburg State University David O'Bryan, (E-mail: obryan@ @ittstate.edu), Pittsburg State University

\begin{abstract}
Research indicates that the direct method of preparing the statement of cash flows is preferred by users (Broome 2004; Knutson 1993). SFAS No. 95 expresses a preference for the direct method, but allows firms to use the indirect method (FASB 1987). This compromise was the result of a concerted lobbying effort by companies who argued the direct method would require costly modifications to their accounting information systems. While this may have been true in the 1980s, technological advances do not justify the continued use of the indirect method when users clearly prefer the direct method.

However, currently available accounting information systems do not generally provide an efficient way to generate a statement of cash flows using the direct method. This article illustrates a work around for preparing the direct method statement using current accounting software, discusses some of the difficulties in using the work around, and suggests some modest changes that software developers could make that would make preparing the direct method statement of cash flows as easy as producing an income statement or a balance sheet.
\end{abstract}

\section{THE DIRECT METHOD IS PREFERRED BUT NOT USED}

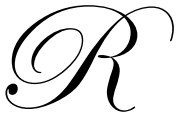

ecent financial reporting scandals have tarnished the reputation of the accounting profession. As our profession seeks to restore its reputation with users, it is more important than ever to provide users with reliable information, on a timely basis, and in the format desired by users. The current approach to preparing and reporting the statement of cash flows is often not timely (Howell 2003), not in the format desired by users (Broome 2004; Knutson 1993), and sometimes unreliable (Romero and Berenson 2002).

The shortcoming of the current approach to preparing and reporting the statement of cash flows presents an excellent opportunity for the accounting profession to demonstrate that it is responsive to users' needs. The current focus on operating cash flows as a means to assess the quality of earnings only heightens the importance of this initiative. We face many difficult challenges in the current financial reporting environment, but this is one area where significant improvement can be made quickly at a nominal cost (Miller and Bahnson 2002).

\section{CURRENT ACCOUNTING SOFTWARE IS INADEQUATE}

One reason most firms use the indirect method to prepare the statement of cash flows is because their accounting information systems are not designed to generate a direct method statement of cash flows. In fact, most software packages do not even produce a correct statement of cash flows using the indirect method. To this day, the current approach to preparing a correct statement of cash flows requires a nontrivial amount of manual intervention.

The accounting software vendors are locked into a historical focus, arising from the old Statement of Changes in Financial Position and the file-based systems that were prevalent before the emergence and growth of relational databases. SFAS No. 95 compounds matters by allowing companies to continue to use the indirect method. Perhaps it is no surprise, then, that while commercial accounting packages easily produce a variety of both balance 
sheets and income statements, they are generally unable to generate correct cash flow statements.

Many packages claim to do so, but fail in this regard. Courtney and Flippen (1995) found that of 15 leading MS-DOS based mid-range accounting packages, all could generate balance sheets and income statements, but none could generate correct cash flow statements even though 14 generated something called a cash flow statement. In a subsequent study of Windows-based packages, Courtney et al. (1998) found that of nine packages, six attempted to generate a cash flow statement and none were successful. While all software packages examined by Courtney were designed for the private sector, Jones (2000) found the same problems in an examination of non-profit packages. Of ten leading packages examined, she found that four made no provision for the cash flow statement and those that did generated incorrect statements. Products ranged from low-end to ERP-type software.

What are some of the defects of the statements generated by the packages?

1. The programs show the net changes in long-term real accounts rather than revealing gross cash inflows and outflows. Thus the issuance of $\$ 30$ million in long-term bonds and the retirement of an earlier $\$ 30$ million issue does not appear on the cash flow statement.

2. All gains and losses on long-term account changes appear in the "Cash Flows from Operations" category. Consequently, the gain on disposition of a fixed asset is shown as an increase in cash flow from operations. Gains and losses on debt retirements and treasury stock transactions similarly affect operating cash flow.

3. Transactions that have no effect on cash are shown otherwise. For example, the acquisition of a fixed asset financed by a current account payable is shown as a cash outflow for investment in fixed assets and an increase in cash from operations.

One package not examined in the above studies-Accountmate-is able to produce a somewhat defective cash flow statement by attaching a special cash flow code to every non-cash account. However, the statement still shows only the net effect of changes in long-term accounts. For example, the acquisition of treasury stock for option granting will be offset by a stock issuance and nothing will appear on the cash flow statement. By astute coding in Accountmate, one can avoid showing gains on fixed asset dispositions as a cash flow from operations.

It is no surprise that accounting software developers would have difficulty in programming an accounting package to generate a correct statement of cash flows using the indirect method. Any student of accounting is aware of the intricacies involved in preparing a cash flow statement using the indirect method as compared with either a balance sheet or income statement. Nor is it surprising that software developers chose to attempt the indirect method given its popularity in accounting practice. However, with a modest change to our accounting information systems we can produce a statement of cash flows using the direct method as quickly and as easily as we can prepare a balance sheet or an income statement.

\section{A TEMPORARY FIX FOR EXISTING SOFTWARE}

Consider how difficult it would be to generate an income statement if we used no temporary accounts and instead ran everything through Retained Earnings? Yet, isn't that exactly what we do with Cash? The income statement (along with the retained earnings statement) is an attempt to explain changes in retained earnings. If income statements were prepared in the same manner as are cash flow statements, we would have no nominal accounts. All balance sheet accounts other than retained earnings would be analyzed and detailed changes in those accounts would comprise the income statement. For example, sales would have to be obtained by selecting credit sales from accounts receivable debits and cash sales from cash account debits. Various expenses would be derived from an analysis of cash credits and account payable credits.

This method of deriving an income statement probably seems archaic. Yet, this is precisely the approach currently taken to prepare a statement of cash flows. All transactions that effect cash are debited or credited directly to a permanent Cash account. At period end, preparers have to analyze balance sheet and income statement accounts to derive the underlying cash flows. 
Bahnson et al. (1996) and Bahnson and Miller (2002) advocate a new approach to the preparation of the statement of cash flows. This approach results in a truly direct approach in that it utilizes temporary Cash accounts to capture all the information needed to prepare the statement of cash flows at the point when data is entered into the accounting information system. Although conceptually appealing, Bahnson and Miller (2002) note,

Of course, we haven't addressed the technical issues that management accountants and financial managers will encounter in modifying their specific software packages to accommodate temporary cash accounts. We encourage you to experiment by creating subsidiary accounts or temporary accounts as allowed by your particular system. p. 57

The technical issues that must be addressed to implement their idea are not overwhelming. Software vendors could make some basic design changes that would easily accommodate their approach. However, until software vendors incorporate these features into their packages there is an effective approach that can be used with existing accounting systems. This simply entails creating nominal cash accounts that are closed to the permanent cash account at period end.

Nominal cash flow accounts may seem odd. As noted earlier, however, the income statement is comprised of temporary accounts related to the Retained Earnings account. Rather than derive revenues and expenses from changes in balance sheet accounts ex post, temporary accounts were created to capture this information when transactions are initially entered into the system.

Just as revenue and expense accounts provide us with the details needed to prepare an income statement from the Retained Earnings account, details of the Cash account can quickly and efficiently provide us with a correct statement of cash flows using the direct method. The major obstacle to this change is our traditional method of recording transactions to the Cash account. If we can agree that detailed information about the Cash account would be useful, then it is relatively easy to modify our systems to make this detailed information readily available.

To illustrate, we begin by specifying in the chart of accounts nominal Cash accounts corresponding to the detail needed to prepare a statement of cash flows. SFAS No. 95 largely dictates the nominal Cash accounts that would be needed to provide a sufficiently detailed statement of cash flows. That is, nominal cash accounts would be created for categories such as:

\section{Nominal Cash Account Title}

Normal Balance

Collections from customers

Dr.

Payments to suppliers

Cr.

Payments for operating expenses

$\mathrm{Cr}$.

Interest paid

Cr.

Income taxes paid

Payments for long-term investments

Proceeds from the disposition of long-term investments

Cr.

Proceeds from the disposition of fixed assets

Payments for the acquisition of fixed assets

Proceeds from the issuance of long-term bonds

Payments for the retirement of long-term bonds

Cr.

Proceeds from the issuance of equity securities

Dr.

Dr.

Payments for cash dividends to stockholders

Cr.

Dr.

Cr.

Dr.

Payments to repurchase stock

Cr.

Cr.

With the establishment of these and other required "cash flow" accounts, and their use for recording cash transactions, all the necessary data will be provided for creation of a direct method cash flow statement directly from the trial balance. For example, the collection of cash from customers will require a debit to Collections from 
Customers and a credit to Accounts Receivable. Likewise, the disposition of a fixed asset at a loss will be recorded as follows:

\begin{tabular}{|lr|}
\hline Accumulated Depreciation & 6 \\
Loss on Fixed Asset Disposition & 1 \\
Cash Proceeds from Fixed Asset Disposition & 3 \\
Fixed Assets & 10 \\
\hline
\end{tabular}

Exhibit I shows the relationship of "cash flow" accounts to conventional income statement accounts. Cash flow accounts are identical to conventional nominal accounts and are treated in the same way. In fact, they are nothing more than a new type of nominal account. Both cash flow accounts and income statement accounts describe data "flows" as opposed to "stocks" that are represented by real accounts. And, both cash flow accounts and income statements accounts will be closed to their associated permanent account at period end. Although we are not accustomed to nominal cash flow accounts, there is conceptually nothing that separates them from nominal income statement accounts.

Exhibit I

\begin{tabular}{|c|c|c|c|c|c|c|c|c|}
\hline \multirow{2}{*}{$\begin{array}{l}\text { Real Accounts } \\
\text { Sample Cash I }\end{array}$} & Cash & $\begin{array}{l}\text { Accounts } \\
\text { Receivable }\end{array}$ & Inventory & $\begin{array}{l}\text { Fixed } \\
\text { Assets }\end{array}$ & $\begin{array}{l}\text { Account } \\
\text { Payable }\end{array}$ & $\begin{array}{l}\text { Long-Term } \\
\text { Bonds }\end{array}$ & $\begin{array}{l}\text { Capital } \\
\text { Stock }\end{array}$ & $\begin{array}{l}\text { Retained } \\
\text { Earnings }\end{array}$ \\
\hline & W Acc & & & & & $\underline{\text { Sample Inco }}$ & me State & nt Accounts \\
\hline $\begin{array}{l}\text { Nominal } \\
\text { Accounts }\end{array}$ & $\begin{array}{l}\text { Colle } \\
\text { Paym } \\
\text { Paym } \\
\text { Incon } \\
\text { Paym } \\
\text { Colle } \\
\text { Paym } \\
\text { Colle } \\
\text { Colle }\end{array}$ & $\begin{array}{l}\text { s from custo } \\
\text { to suppliers } \\
\text { for operating } \\
\text { xes paid } \\
\text { for fixed ass } \\
\text { os for fixed a } \\
\text { for stock inv } \\
\text { s for stock d } \\
\text { for bond iss }\end{array}$ & $\begin{array}{l}\text { ers } \\
\text { expenses } \\
\text { ts } \\
\text { et dispositions } \\
\text { stments } \\
\text { positions } \\
\text { ance }\end{array}$ & & & $\begin{array}{l}\text { Sales } \\
\text { Cost of } \\
\text { Sales S } \\
\text { Sales T } \\
\text { Advert } \\
\text { Admin } \\
\text { Deprec } \\
\text { Repair } \\
\text { Income }\end{array}$ & $\begin{array}{l}\text { f Sales } \\
\text { Salaries } \\
\text { Cravel Ex } \\
\text { ising } \\
\text { istration } \\
\text { ciation Ex } \\
\text { s Expens } \\
\text { e Tax Ex }\end{array}$ & $\begin{array}{l}\text { se } \\
\text { ges } \\
\text { nse } \\
\text { se }\end{array}$ \\
\hline
\end{tabular}

\section{Implementing the work around}

There are at least two possible ways to implement nominal accounts for a computerized accounting system. The most obvious is to mimic the creation of nominal accounts for the income statement. These usually come at the end of the chart of accounts, adjacent to the retained earnings account. Therefore, numbering schemes originate with real accounts and continue to nominal accounts. But cash is usually at the beginning of the account numbering scheme. If cash flow accounts are to be adjacent to the cash account, the numbering scheme could begin with the cash flow (nominal) accounts, continue with the balance sheet (real) accounts, and conclude with the income statement (nominal) accounts. Such a simplified chart of accounts appears on the left side of Exhibit II.

A second method of implementing cash flow accounts is the commonly used master account/subaccount/normal account system. Master accounts have a description, but no balances and no entries are made to them. Sub-accounts are normal in all respects except that they belong to a master account, and the sub-account balances may be added by the accounting software, with the totals displayed as the balance of the related master account. Normal accounts do not have sub-accounts and have balances. 
Exhibit II: Illustrative Charts of Accounts

\begin{tabular}{|c|c|c|c|}
\hline \multicolumn{2}{|r|}{ All Normal Accounts } & \multicolumn{2}{|r|}{ Master/Sub/Normal Accounts } \\
\hline 1001 & Collections from Retail Customers & 100.0 & Cash \\
\hline 1002 & Collections from Wholesale Customers & 100.1 & Collections from Customers \\
\hline 1003 & Collections from Misc. Sales & 100.2 & Payments to Suppliers \\
\hline 2001 & Payments to Domestic Suppliers & 100.3 & Payments for Operating Expenses \\
\hline 2002 & Payments to Euro Suppliers & 100.4 & Income Taxes Paid \\
\hline 2101 & Salary and wage payments & 100.5 & Payments for fixed assets \\
\hline 2102 & Supplies payments & 100.6 & Collections for fixed asset dispositions \\
\hline 2103 & Advertising payments & 100.7 & Payments for stock investments \\
\hline 2201 & Federal Income Tax Payments & 100.8 & Collections for stock dispositions \\
\hline 2202 & State Income Tax Payments & 100.9 & Collection for bond issuance \\
\hline 2301 & Payments for Machinery & 111.0 & Accounts Receivable \\
\hline \multirow[t]{4}{*}{2302} & Payments for Vehicles & 121.0 & Inventory \\
\hline & - & 141.0 & Fixed Assets \\
\hline & $\bullet$ & 201.0 & Accounts Payable \\
\hline & - & & $\bullet$ \\
\hline 3001 & Cash & & $\bullet$ \\
\hline 3002 & Accounts Receivable & & • \\
\hline \multirow[t]{4}{*}{3003} & Inventory & 500.0 & Sales \\
\hline & - & 500.1 & Sales-wholesale \\
\hline & $\bullet$ & 500.2 & Cost of Sales-Retail \\
\hline & - & & - \\
\hline 5001 & Sales-retail & & $\bullet$ \\
\hline 5002 & Sales-wholesale & & $\bullet$ \\
\hline \multirow[t]{4}{*}{6001} & Cost of Sales-Retail & & $\bullet$ \\
\hline & - & & $\bullet$ \\
\hline & - & & $\bullet$ \\
\hline & $\bullet$ & & $\bullet$ \\
\hline
\end{tabular}

Note: Master and normal accounts are boldface and have a zero after the decimal.

Therefore, reports can be produced showing the ledger detail (sub-accounts and normal accounts) or by showing only master account and normal account balances. Those entities not requiring comprehensive cash budgeting would likely adopt master/sub-accounts as the form of implementation. The right side of Exhibit II illustrates a chart of account scheme for the master/sub/normal account approach.

Note that the right side of Exhibit II assumes that master/sub-accounts are used for sales as well as cash. In fact, they would often be used for a large number of accounts, and might even be invoked for the chart of accounts on the left side of the exhibit, with, for example, a further subdivision of the account Payments to Euro Suppliers. Note that in Exhibit II, the account numbers on the left have only one field while those on the right have two. Since some software packages provide several fields composing the account numbers, a large variety of schemes may be used in practice.

Another significant advantage of the master/sub/normal account methodology is that accountants may immediately implement it and begin to easily obtain cash flow statements despite the inadequacies of extant accounting software packages with respect to generating an accurate statement of cash flows.

\section{CHALLENGES WITH EXISTING SOFTWARE}

The primary difficulties of using the temporary fix are (1) doing a manual closing of these "nominal" cash accounts and (2) overcoming misconceptions on the part of practitioners. A manual closing of these cash flow accounts will have to be at the chart of account level. Thus, at period-end, a journal entry will have to be prepared to empty all the nominal cash accounts into their permanent, real accounts. While this is not a difficult task, it might be a time-consuming task for firms with many nominal cash accounts. This could be automated using Excel and 
importing/exporting the journal entry, however. Consequently, we do not view this as a major obstacle.

Overcoming misconceptions on the part of practitioners is more serious. Conversations with CPAs have resulted in remarks such as "the direct method is so much more difficult". In fact, the direct method would be easier than the current indirect method with this coding scheme. But it is difficult to convince people that an unfamiliar, simple concept is easier than a familiar, complex concept. Also, some preparers may not be familiar enough with their software to understand how to implement these measures. This makes the work around seem much more difficult than it is.

Finally, preparers that earn fees by preparing the indirect method statement of cash flows may be reluctant to automate that task using our coding scheme. What is proposed here would enable firms to generate a direct method statement of cash flows as quickly and easily as they can generate an income statement or balance sheet. Rather than viewing this as a threat, preparers should realize that this method will allow them to provide higher value added services such as assisting with analyzing and forecasting cash flows.

\section{AN APPEAL TO SOFTWARE VENDORS}

When providing "canned" Balance Sheets and Income Statements, commercial software vendors rely upon a field variously called "Account Type" or "Account Category" to build the basic financial statements. (See Exhibits III and IV). These fields allow the user to specify any coding structure they like for their chart of accounts and still make use of pre-programmed Balance Sheets and Income Statements. With the addition of just three new account types: Cash Flows from Operating Activities, Cash Flows from Investing Activities, and Cash Flows from Financing Activities, it would be possible for software vendors to provide us with a "canned" Statement of Cash Flows using the direct method.

\section{Exhibit III}

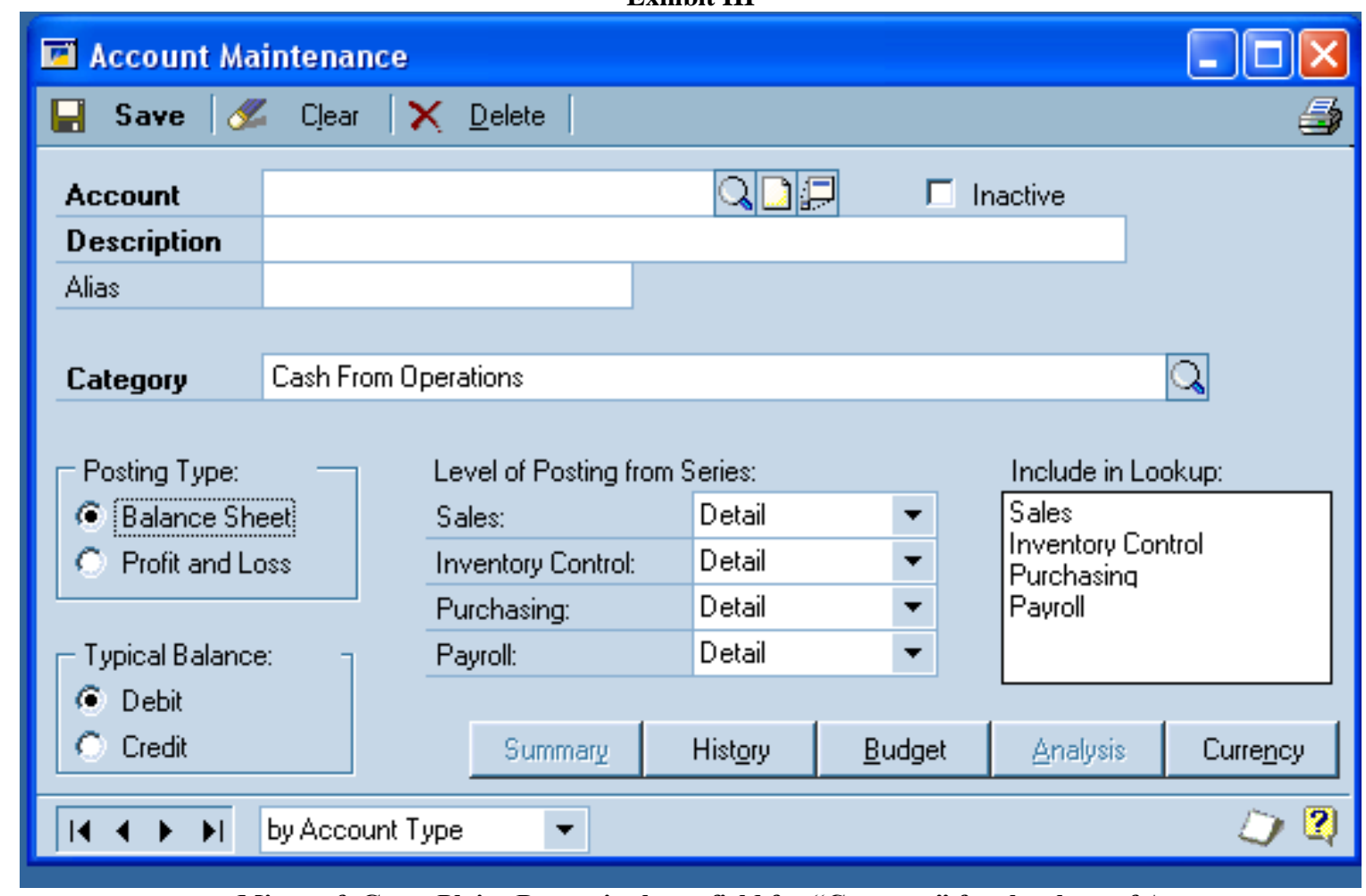

Microsoft Great Plains Dynamics has a field for "Category" for the chart of Accounts 


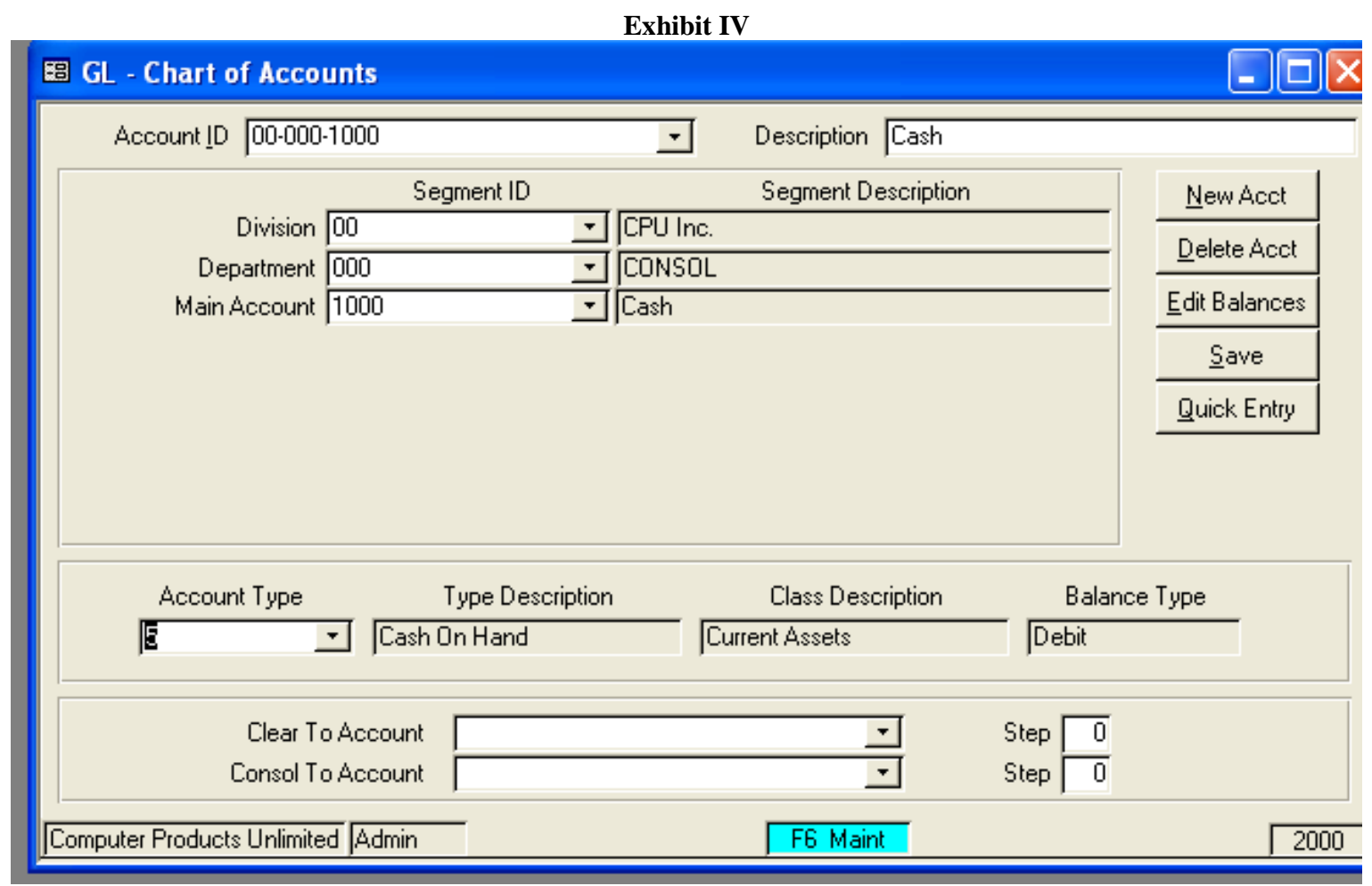

Traverse has an Account Type and Class Description.

A few software packages allow the user to set up new account types, but many of these packages do not allow the user to add to or edit the account type field. Many software packages have a "hard-coded" field so that even when the source code is provided, the user cannot alter this particular field. This is done to ensure the integrity of the prepackaged financial statements. Thus, software vendors need to provide the user with account types suitable for cash flow statements and these account types must be used for both

\section{Balance Sheet and Cash Flow Statements}

But the full benefits of detailed cash budgeting and reporting will only become available when accounting software developers implement nominal accounts for cash. We believe accounting systems should allow a user to create, in essence, temporary cash accounts corresponding to the common line items on a direct method statement of cash flows. As cash flows were entered they would be coded into their appropriate statement of cash flow category/account, just as revenues and expenses are coded into their appropriate accounts when they are initially entered into the system. At period end, the bulk of the work for the statement of cash flows would already be done and the statement could be generated much more efficiently than it is now.

Currently, most commercially available software assumes that all nominal accounts will be closed to retained earnings. No provision is made, in most packages, for closing to an account other than one designated as an equity account. Also, most packages allow closing to only one account. (See Exhibit V) Our scheme requires being able to close nominal cash accounts to one or more real cash accounts as well as closing revenue and expense accounts to the retained earnings account. Software vendors need to add this ability to both create nominal cash flow accounts and close those accounts to various real cash accounts. 


\section{Exhibit V}

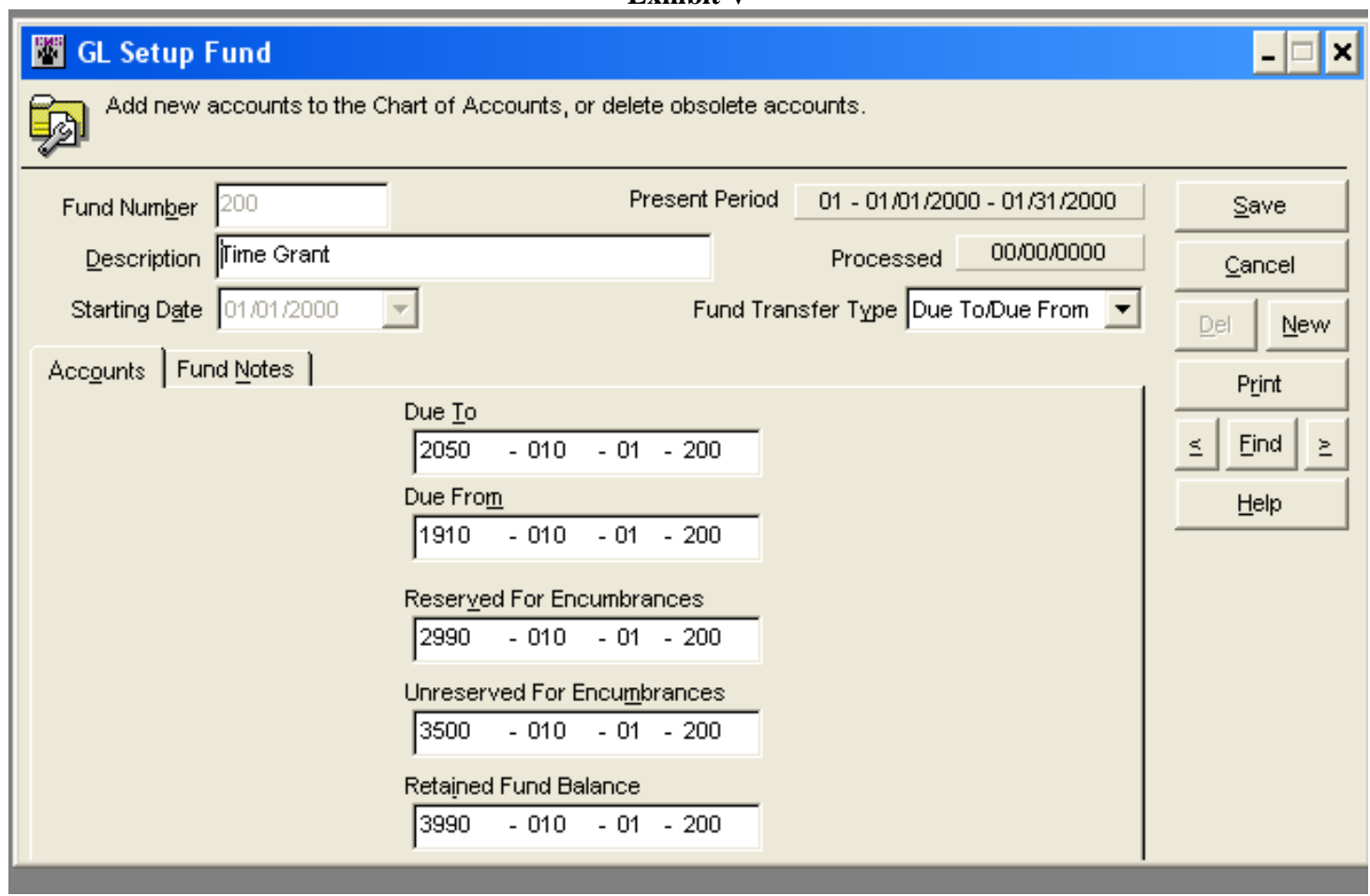

The GL Account Set Up Screen for Cougar Mountain Fund Accounting Software indicating that only one Retained Fund Balance Account can be used for closing.

Not surprisingly these attributes are available in some of the higher-end software packages already. J.D. Edwards and Axapta, for example, can already be configured, not necessarily easily, to produce a direct statement of cash flows using the method described in this article (although they do not yet provide one with their packages). Other software developers tell us that while this could be done it would require reprogramming the software. However, unless there is demand from their customers, or an accounting standard requiring the use of the direct method, they are unlikely to modify their existing products.

\section{AN APPEAL TO THE FASB}

The FASB initially sought to require the direct method for the statement of cash flows. Preparers objected, largely on the grounds that the direct method would be too costly for them to implement. Although this may have been true when SFAS No. 95 was issued in 1987, technological advancements since then make this argument implausible. In our discussions with software vendors, they readily acknowledge that their systems could be modified, at a reasonable cost, to automatically generate a direct method statement of cash flows. However, they question the value proposition when their customers are not currently demanding this feature.

Despite much research indicating that users prefer the direct method statement of cash flows, most companies use the indirect method. One reason may simply be that this is the status quo and there is no compelling reason to change. A second reason may be that their systems will not generate a direct method statement of cash flows. However, as noted above, this could be remedied but not until companies demand this feature from their software vendors. Hence, we have the proverbial chicken or the egg scenario. Software vendors have no incentive to provide this feature and companies won't try this new approach unless it is readily available in their systems.

A third reason may be that companies are resisting the direct method of reporting because it is more 
transparent and more easily understood by users. That is, perhaps companies perceive that using the direct method would disclose too much information to the public and their competitors. Whatever the reason(s), the net result is likely to be a continuation of the status quo, unless there is a compelling reason to change.

We believe that the overwhelming desire by users for the direct method is a compelling reason to change. Now more than ever, the accounting profession needs to be responsive to users' needs. Consequently, we appeal to the FASB to amend SFAS No. 95 to require the direct method. This requirement will create the demand by companies for an efficient means to generate the report, which in turn will provide software vendors with an incentive to offer this feature. The FASB was correct in its initial deliberations on this issue, but yielded to practical concerns about the cost of implementation. Technological advancements now make this concern a moot issue.

Far from being a costly change for companies, we believe it could have a number of advantages for them. First, several companies we visited with acknowledged using the direct method internally because it was more closely aligned with their cash management and forecasting systems. Using the direct method for external reporting would therefore allow software vendors to provide their customers with a system that integrated cash management and forecasting into their financial reporting package.

Second, if software vendors modified their systems as we recommend, the statement of cash flows could be generated automatically. This would save time for preparers and also allow companies to provide users with cash flow reports contemporaneous with earnings reports, which is currently not the case (Howell 2003).

Third, capturing details about cash flows at the recording stage could make the implementation of other accounting requirements less burdensome. For example, one company we interviewed noted that SFAS No. 121 requires entities to track cash flows down to the business unit and even plant level to determine whether an asset was impaired. They noted that our recommended system would allow them to generate this information much more easily than with their current, traditional approach.

Fourth, since users prefer the direct method, companies could benefit from a lower cost of capital by providing cash flow information in the format desired by the capital markets.

Fifth, auditors may reap a benefit from this approach too. Detailed recording of cash flows in the manner we prescribe would make computerized audits of cash flows quite easy. For example, a bank loan should have an offsetting debit to Cash Inflows from Borrowing. If a computerized audit routine noted a debit to, say, Cash Collections from Customers a potential misclassification in the statement of cash flows could be corrected. Although verification of the beginning and ending cash balances ensures that the stock of cash is accurately reported, capturing details about the flow of cash would help ensure that cash flows are appropriately classified within the statement of cash flows. As we have now learned with Worldcom (reporting operating cash outflows as investing cash outflows) and Enron (reporting financing cash inflows as operating cash inflows), appropriate classification of cash flows is just as important as verifying the account balance.

Lastly, educators will benefit from a truly direct approach to reporting cash flows. Not only is the indirect method confusing for users, it is also very difficult for accounting students to comprehend. At best, many students resort to memorizing the steps needed to prepare a statement of cash flows using the indirect method. In addition, Bahnson et al. (1996) demonstrate that the commonly used approach to teaching the statement of cash flows is not accurate in practice. The direct approach illustrated in this article resolves these issues for educators and their students.

\section{RECONCILIATION OF CASH FLOW AND EARNINGS}

While the indirect method of preparing a cash flow statement shows a reconciliation of earnings with the net change in cash, this data is not inherent in the direct method cash flow statement. Thus, generally accepted accounting principles require the reconciliation as an appendage or footnote to the cash flow statement. Certainly, this information is useful for a full understanding of entity operations. 
But the reconciliation of cash flow and earnings is no more associated with a direct method cash flow statement than it is with the income statement. It is a reconciliation of the difference between two equally important statements that have a somewhat different perspective. Therefore, the reconciliation should be included as a footnote to the statements as a group rather than being associated uniquely with the cash flow statement.

\section{CONCLUSIONS}

Accounting software developers have not developed packages that will generate correct cash flow statements due to the intricacies associated with the indirect method for cash flow statements. Accounting software companies have not been able to deliver products that produce cash flow statements because they, as well as the accounting profession, have a perspective of the statement based upon history, i.e. the sources and applications of working capital statement. The true nature of the cash flow statement has been obscured because it evolved from this predecessor rather than being viewed in the same perspective as the income statement.

The methodology described here will enable cash flow statements to be generated using the same logic used to prepare income statements. It will also, hopefully, result in the development of such programs. And if no such programming is forthcoming, the widespread use of report generators such as Crystal Reports or FRx will enable knowledgeable users to generate a cash flow statement from a chart of accounts designed as suggested here with existing software.

The Financial Accounting Standards Board has advocated the direct method of calculating cash flow as being preferable to the indirect method (FASB 1987). The FASB has not required the direct method because of system difficulties that probably existed at the time this standard was set. Given that these difficulties no longer exist with the move from file-based systems to database systems, it is time the FASB follow the lead of our Australian colleagues who required the direct method in 1992 under Approved Australian Accounting Standard AASB 1026 "Statement of Cash Flows". By enabling an easy method of statement generation, the preferable method should become more commonly used. Undoubtedly, managers not trained in accounting will more easily understand the direct than the indirect method.

A final benefit may, over the long run, be the most important. Cash budgeting in accounting software today is at best, ad hoc, incomplete, and lacking in detail. Entities requiring a comprehensive cash budgeting system are usually required to use either spreadsheets or an independent budgeting package. Neither approach integrates well with the accounting system. A comprehensive system of cash flow budgeting within the accounting information system has the potential of making a significant contribution to more effective use and control of cash. The proposed creation and use of cash flow accounts in the general ledger will enable such a system that is logical, comprehensive, and possesses the discipline of the double entry system.

This implementation method has the advantage of accommodating a large number of cash flow accounts, perhaps even approaching or exceeding the number of income statement accounts. At present cash flow budgeting is ad hoc and not cleanly integrated with accounting systems. Providing detailed cash flow budgeting within the accounting model would be a significant benefit since each cash flow account could have fields for budgeted cash flow by the month or week as do income statement accounts.

By viewing the cash flow statement as a detailing of the cash account, in the same manner as the combined income and retained earnings statement details the retained earnings account, a methodology for collecting data emerges. The cash flow statement can be abstracted from an entity trial balance in the same manner that an income statement is obtained. This converts a task is awkward for preparers and yields information that is confusing for users into a simple, convenient routine that simultaneously adds a cash budgeting dimension to the accounting information system and provides more useful information to users. 


\section{REFERENCES}

1. Bahnson, P., P. Miller, and B. Budge. 1996. "Nonarticulation in Cash Flow Statements and Implications for Education, Research, and Practice". Accounting Horizons 10(4). December: 1-15.

2. Broome, O. Whitfield. 2004. "Statement of Cash Flows: Time for Change!" Financial Analysts Journal. March/April: 16-22.

3. Courtney, H. and C. Flippen. 1995. “A Shopper's Guide to Accounting Software”. Journal of Accountancy 179(2), February: 37-59.

4. Courtney, H., C. Prachyl, and T. Glandon. 1998. "Guide to Accounting Software". Journal of Accountancy 185(3), March: 44-61.

5. FASB. 1987. "Statement of Financial Accounting Standards No. 95", Statement of Cash Flows. Financial Accounting Standards Board. November.

6. Howell, M. 2003. "Disclosure Moves at Snail's Pace”. Reuters. Saturday, July 19.

7. Jones, R. 2000. "Sizing Up NPO Software". Journal of Accountancy 190(5), November: 28-44.

8. Knutson, P. 1993. "Financial Reporting in the 1990s and Beyond". Charlottesville, VA: Association for Investment Management and Research, 1993 Position Paper.

9. Miller, P. and P. Bahnson. 2002. "Fast Track to Direct Cash Flow Reporting". Strategic Finance, February: 51-57.

10. Rombero, S. and A. Berenson. 2002. "Worldcom Says It Hid Expenses, Inflating Cash Flow by \$3.8 Billion". New York Times. Wednesday, June 26: Section A, Page 1, Column 1.

\section{NOTES}


NOTES 